\title{
Association between Nonspecific Chronic Lymphocytic Thyroiditis and Differentiated Epithelial Thyroid Carcinoma: Clinicopathological Analysis of Patients Who underwent Thyroidectomy in a Tertiary Care Center in Sri Lanka
}

\author{
${ }^{1}$ Nadeesha J Nawarathna, ${ }^{2}$ Palitha Ratnayake, ${ }^{3}$ Suwin N Hewage, ${ }^{4}$ Ranjith JK Senevirathne, ${ }^{5}$ Sonali SC Gunatilake \\ ${ }^{6}$ Nimeda L Kariyawasam, ${ }^{7}$ Rasika Shyamalie, ${ }^{8}$ Priyanga Yogachandran
}

\begin{abstract}
Introduction: The most common differentiated malignant thyroid neoplasm is papillary carcinoma. The association of concurrent presence of chronic lymphocytic thyroiditis and its subtypes with differentiated epithelial thyroid carcinoma remains controversial.

Objective: To evaluate the epidemiological factors of chronic lymphocytic thyroiditis and association between chronic lymphocytic thyroiditis and its subtypes with differentiated epithelial thyroid carcinoma.
\end{abstract}

Materials and methods: The histopathological records of 684 patients who underwent thyroidectomy at Teaching Hospital Kandy, Sri Lanka, for a period of 21/2 years from January 2013 were reviewed. Their clinical and pathological characteristics were analyzed. Chronic lymphocytic thyroiditis was diagnosed by histology.

Results: Thyroid malignancies were detected in $14.2 \%$ of thyroidectomy specimen, of which well-differentiated epithelial thyroid carcinoma was seen in $82 \%$. Chronic lymphocytic thyroiditis was present in $31 \%$, out of which $73.1 \%$ were nonspecific chronic lymphocytic thyroiditis and $26.9 \%$ were Hashimoto's thyroiditis. Gender, age, and presence of thyroiditis were significantly associated with papillary thyroid carcinoma. In the analyzed sample, males were more likely to have papillary carcinoma compared with females $(p=0.013)$. Those with nonspecific chronic lymphocytic thyroiditis were more likely to have papillary thyroid carcinoma $(p=0.002)$ compared with

\footnotetext{
1,5 Senior Registrar, ${ }^{2}$ Consultant Pathologist, ${ }^{3}$ Assistant Lecturer ${ }^{4}$ Consultant Surgeon, ${ }^{6,8}$ Intern Medical Officer, ${ }^{7}$ Research Assistant

1,4,6,8 Department of Surgery, Teaching Hospital Kandy, Kandy Sri Lanka

${ }^{2}$ Department of Pathology, Teaching Hospital Kandy, Kandy Sri Lanka

${ }^{3}$ Medical Education Unit, University of Kelaniya, Colombo, Sri Lanka

${ }^{5}$ Department of Endocrine, Colombo South Teaching Hospital Colombo, Sri Lanka

${ }^{7}$ Department of Science, University of Peradeniya, Mawanella Sri Lanka

Corresponding Author: Nadeesha J Nawarathna, Senior Registrar, Department of Surgery, Teaching Hospital Kandy Kandy, Sri Lanka, e-mail: nadeeshanawarathna@yahoo.com
}

those without. With increasing age, the proportion of lymphovascular invasion in patients with papillary thyroid carcinoma significantly $(p=0.010)$ decreases. None of the three factors mentioned were significant predictors of presence of follicular carcinoma, tumor focality, capsular or lymphovascular invasion in papillary or follicular carcinoma.

Conclusion: The presence of nonspecific chronic lymphocytic thyroiditis is associated with papillary thyroid carcinoma at a given age and gender. Influence of nonspecific chronic lymphocytic thyroiditis on the prognosis of well-differentiated epithelial thyroid carcinoma needs to be investigated further with a larger sample size.

Keywords: Age, Differentiated thyroid carcinoma, Gender, Nonspecific chronic lymphocytic thyroiditis.

How to cite this article: Nawarathna NJ, Ratnayake P, Hewage SN, Senevirathne RJK, Gunatilake SSC, Kariyawasam NL, Shyamalie R, Yogachandran P. Association between Nonspecific Chronic Lymphocytic Thyroiditis and Differentiated Epithelial Thyroid Carcinoma: Clinicopathological Analysis of Patients Who underwent Thyroidectomy in a Tertiary Care Center in Sri Lanka. World J Endoc Surg 2018;10(2):119-126.

Source of support: Nil

Conflict of interest: None

\section{INTRODUCTION}

Well-differentiated thyroid carcinoma and chronic lymphocytic thyroiditis are commonly encountered conditions in clinical practice. The most common malignant neoplasm of the thyroid is papillary thyroid carcinoma, comprising 70 to $80 \%$ of all thyroid cancers. Chronic lymphocytic thyroiditis is one of the most prevalent autoimmune endocrine diseases predominantly affecting females. It is the commonest cause of hypothyroidism in iodine-sufficient areas. ${ }^{1,2}$ Since Dailey et al $^{3}$ first proposed a relationship between Hashimoto's thyroiditis and papillary thyroid carcinoma in 1955, there had been several studies with conflicting conclusions. Some authors concluded that there is a positive correlation between chronic lymphocytic thyroiditis and papillary thyroid carcinoma, ${ }^{3-9}$ whereas others did not. ${ }^{10-14}$

Chronic inflammation has been well established as a risk factor for the development of certain malignant 


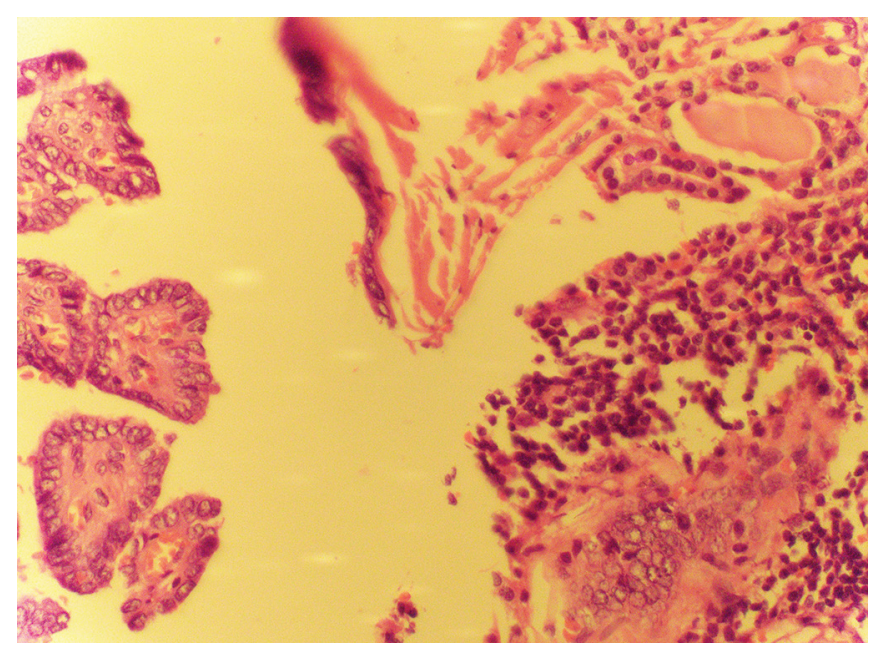

Fig. 1: Papillary carcinoma with chronic nonspecific lymphocytic thyroiditis (high-power field)

tumors. Lymphocytic infiltration is frequently observed in differentiated thyroid carcinoma, suggesting that immunological factors might be involved in tumor progression. ${ }^{15,16}$ However, with respect to these two entities, the association of cause and effect between them remains uncertain.

Chronic lymphocytic thyroiditis as well as differentiated thyroid carcinoma may be asymptomatic for a long period and diagnosed incidentally on histological examination of thyroidectomy specimen. Most of the thyroid specimens harbored chronic lymphocytic thyroiditis. However, characteristic features of Hashimoto's thyroiditis, such as Hurthle cell changes were not observed in most of the histological examinations. The lymphocytic infiltrate is focal and lymphoid follicle formation is rare in this form of chronic lymphocytic thyroiditis. It is observed that this form of nonspecific lymphocytic thyroiditis also coexisted with differentiated thyroid carcinoma (Figs 1 to 3). Some authors related this form of thyroiditis to inadvertent use of iodide salt, which had led

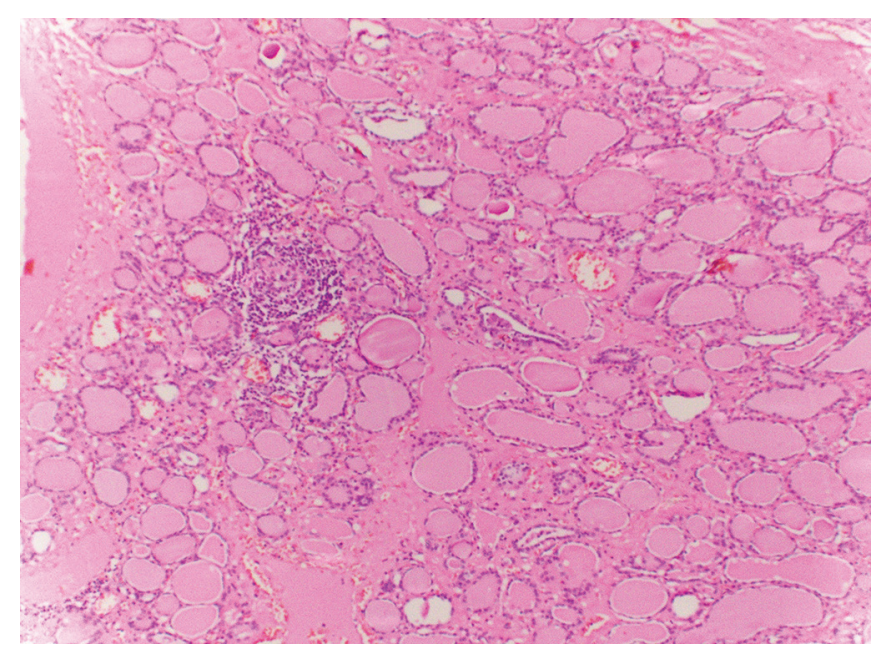

Fig. 3: Chronic nonspecific lymphocytic thyroiditis

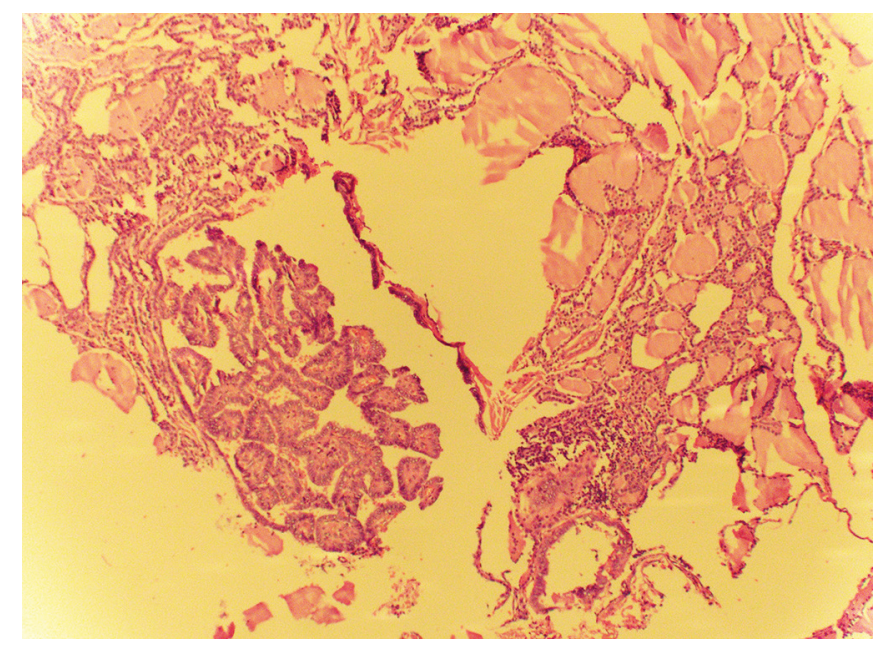

Fig. 2: Papillary carcinoma with chronic nonspecific lymphocytic thyroiditis (low-power field)

to destruction of the thyroid gland itself due to chronic inflammatory reaction. ${ }^{17}$

The results of most of the studies do not lead to definitive conclusions. Some evidence suggests that nonspecific focal or multifocal lymphocytic infiltrates may occur more frequently in cases of papillary thyroid carcinoma, possibly indicating that the tumor can exert some degree of influence on the rest of the gland. Some authors have reported that the presence of chronic lymphocytic thyroiditis, especially Hashimoto's thyroiditis, in patients with papillary thyroid carcinoma is associated with a less aggressive clinical presentation and course ${ }_{1}^{18-20}$ while other studies have not found a similar effect. ${ }^{5,21,22}$ The objective of this study was to evaluate the prevalence of an association between chronic lymphocytic thyroiditis and well-differentiated thyroid carcinoma, and to compare clinicopathological characteristics of patients with well-differentiated thyroid carcinoma in association with the presence or absence of chronic lymphocytic thyroiditis in a large institutional series of patients who underwent thyroidectomy.

\section{MATERIALS AND METHODS}

\section{Patients}

The histopathological records of all the patients with goiters who underwent total thyroidectomy irrespective of the underlying indication at Teaching Hospital, Kandy, Sri Lanka, within the period from January 2013 to June 2015 were reviewed. A total of 702 thyroidectomy specimen reports were initially included in the study. Out of these, 684 were used in the final analysis after excluding cases with missing data. The following variables were entered into a dedicated database: age and gender of patient; presence of chronic lymphocytic thyroiditis and its subtype (Hashimoto's thyroiditis or nonspecific chronic lymphocytic thyroiditis); presence of malignancy 
and its type; in those with malignancy, presence of capsular invasion, presence of lymphovascular invasion, multifocality, and tumor size.

\section{Definitions and Pathology}

The diagnosis of chronic lymphocytic thyroiditis and its subtypes was based on histopathological findings. Thyroiditis was divided in to Hashimoto's thyroiditis and nonspecific chronic lymphocytic thyroiditis depending on the presence of Hurthle cell changes and dense perifollicular lymphocytic infiltration with reactive lymphoid follicle formation, which is seen in Hashimoto's thyroiditis and absent or seen in lesser degree in nonspecific chronic lymphocytic thyroiditis.

In this study, tumors were considered multifocal when two or more malignant foci were found in the same gland. Capsular invasion was determined based on the evidence of tumor infiltration beyond the capsule of the thyroid gland on microscopic examination. All data were collected by the same researcher and all pathologic reviews were performed by the same consultant pathologist.

\section{Statistical Analysis and Ethical Aspect}

Univariate statistics, such as frequencies, percentages, means, and standard deviations were calculated in describing the data. Multiple logistic regression was used in modeling binary response variables, such as the presence of thyroid malignancy, lymphovascular/ capsular invasion, and the presence of multifocality of the tumor. Multiple linear regression was performed in analyzing the relationship of tumor size with predictor variables. All tests considered a significance level of $5 \%$. The authors guaranteed the preservation of data and the confidentiality of the material obtained. Ethical approval was obtained from the institutional ethical review board.

\section{RESULTS}

Out of the 684 thyroidectomy specimen reports considered within the study period, 611 (89\%) were from female patients. The mean age of patients who had undergone
Table 1: Frequency of the different types of thyroid malignancies documented in the histopathological reports

\begin{tabular}{ll}
\hline Thyroid malignancy type & Frequency (\%) \\
\hline Papillary & $54(55.7)$ \\
Follicular & $26(26.8)$ \\
Medullary & $8(8.2)$ \\
Lymphoma & $4(4.1)$ \\
Other & $5(5.2)$ \\
\hline Total & $97(100.0)$ \\
\hline
\end{tabular}

thyroidectomy was 48.0 years [standard deviation $(S D)=12.5$ ]. Histopathological reports on the surgically removed thyroid specimens indicated the presence of chronic lymphocytic thyroiditis in 212 (31.0\%), out of which 57 (26.9\%) had Hashimoto's thyroiditis and 155 (73.1\%) had nonspecific chronic lymphocytic thyroiditis without Hurthloid changes. The presence of malignancy was established in $97(14.2 \%)$ of the cases. The types and frequencies of thyroid malignancies detected are shown in Table 1 . There were 43 cases where the thyroid harbored malignancy together with chronic lymphocytic thyroiditis.

Of the specimens with malignancy, $49.5 \%$ showed lymphovascular invasion and $51.6 \%$ had capsular invasion. Multifocal tumors constituted $28.7 \%$ of the malignancies. The size of tumors ranged from $3 \mathrm{~cm}$ to $120 \mathrm{~cm}$ with a mean of $28.3 \mathrm{~cm}(\mathrm{SD}=26.6)$.

To study the association of differentiated thyroid carcinoma with chronic lymphocytic thyroiditis, logistic regression analysis was performed. Presence of malignancy was modeled using the dependent variables: type of thyroiditis (categories being: No thyroiditis, Hashimoto's thyroiditis, and nonspecific chronic lymphocytic thyroiditis), age, and gender. The analyses were done separately for papillary and follicular carcinoma.

When analyzing the 54 cases of papillary carcinoma, all three factors considered were significant predictors of presence or absence of papillary carcinoma (Table 2).

Gender was significant at $p=0.013$. Males were more likely to have papillary carcinoma in our population compared with females. The odds ratio was 2.603 [95\% confidence interval $(\mathrm{CI})=1.227-5.523]$, which means that males had 2.6 times the odds of developing papillary

Table 2: Logistic regression analysis output for the presence of papillary carcinoma of thyroid

\begin{tabular}{|c|c|c|c|c|c|}
\hline \multirow[b]{2}{*}{ Model terms } & \multirow[b]{2}{*}{ Estimate (beta) } & \multirow[b]{2}{*}{ Significance ( $p)$} & \multirow[b]{2}{*}{ Odds ratio } & \multicolumn{2}{|c|}{$95 \% \mathrm{Cl}$ for odds ratio } \\
\hline & & & & Lower & Upper \\
\hline Gender (male) ${ }^{a}$ & 0.957 & 0.013 & 2.603 & 1.227 & 5.523 \\
\hline Age & -0.044 & $<0.001$ & 0.957 & 0.934 & 0.981 \\
\hline Thyroiditis $^{\mathrm{b}}$ & & 0.007 & & & \\
\hline Thyroiditis (Hashimoto) & -0.143 & 0.822 & 0.867 & 0.251 & 2.993 \\
\hline Thyroiditis (nonspecific) & 0.939 & 0.002 & 2.557 & 1.397 & 4.680 \\
\hline Constant (intercept) & -0.892 & 0.102 & & & \\
\hline
\end{tabular}

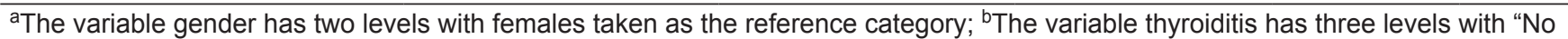
thyroiditis" taken as the reference category, with the other two being Hashimoto's and nonspecific lymphocytic thyroiditis 
Table 3: Logistic regression analysis output for the presence of lymphovascular invasion in papillary carcinoma of thyroid

\begin{tabular}{|c|c|c|c|c|c|}
\hline \multirow[b]{2}{*}{ Model terms } & \multirow[b]{2}{*}{ Estimate (beta) } & \multirow[b]{2}{*}{ Significance $(p)$} & \multirow[b]{2}{*}{ Odds ratio } & \multicolumn{2}{|c|}{$95 \%$ Cl for odds ratio } \\
\hline & & & & Lower & Upper \\
\hline Gender (male) ${ }^{a}$ & 0.779 & 0.318 & 2.180 & 0.472 & 10.072 \\
\hline Age & -0.091 & 0.010 & 0.913 & 0.852 & 0.979 \\
\hline Thyroiditis $^{b}$ & & 0.707 & & & \\
\hline Thyroiditis (Hashimoto) & 1.263 & 0.405 & 3.535 & 0.182 & 68.823 \\
\hline Thyroiditis (nonspecific) & 0.101 & 0.879 & 1.106 & 0.302 & 4.044 \\
\hline Constant (intercept) & 2.679 & 0.052 & & & \\
\hline
\end{tabular}

${ }^{\text {a }}$ The variable gender has two levels with females taken as the reference category; ${ }^{\text {b}}$ The variable thyroiditis has three levels with "No thyroiditis" taken as the reference category, with the other two being Hashimoto's and nonspecific lymphocytic thyroiditis

Table 4: Logistic regression analysis output for the presence of capsular invasion in papillary carcinoma of thyroid

\begin{tabular}{|c|c|c|c|c|c|}
\hline \multirow[b]{2}{*}{ Model terms } & \multirow[b]{2}{*}{ Estimate (beta) } & \multirow[b]{2}{*}{ Significance $(p)$} & \multirow[b]{2}{*}{ Odds ratio } & \multicolumn{2}{|c|}{$95 \% \mathrm{Cl}$ for odds ratio } \\
\hline & & & & Lower & Upper \\
\hline Gender (male) ${ }^{a}$ & -0.061 & 0.935 & 0.941 & 0.218 & 4.062 \\
\hline Age & -0.039 & 0.168 & 0.962 & 0.910 & 1.016 \\
\hline Thyroiditis $^{b}$ & & 0.897 & & & \\
\hline Thyroiditis (Hashimoto) & -0.235 & 0.863 & 0.790 & 0.055 & 11.429 \\
\hline Thyroiditis (nonspecific) & 0.242 & 0.693 & 1.274 & 0.382 & 4.243 \\
\hline Constant (intercept) & 0.753 & 0.520 & 2.123 & & \\
\hline
\end{tabular}

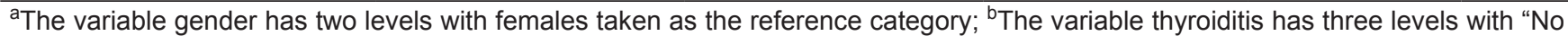
thyroiditis" taken as the reference category, with the other two being Hashimoto's and nonspecific lymphocytic thyroiditis

Table 5: Logistic regression analysis output for the presence of multifocality in papillary carcinoma of thyroid

\begin{tabular}{lllllc}
\hline & & & & \multicolumn{2}{c}{ 95\% Cl for odds ratio } \\
\cline { 4 - 6 } Model terms & Estimate (beta) & Significance (p) & Odds ratio & Lower & Upper \\
\hline Gender (male) ${ }^{\mathrm{a}}$ & -0.127 & 0.868 & 0.881 & 0.196 & 3.958 \\
Age & -0.047 & 0.104 & 0.954 & 0.901 & 1.010 \\
Thyroiditis & & 0.417 & & \\
Thyroiditis (Hashimoto) $_{\text {Thyroiditis (nonspecific) }}$ & 1.407 & 0.303 & 4.085 & 0.280 & 59.621 \\
Constant (intercept) & 0.638 & 0.306 & 1.893 & 0.557 & 6.430 \\
\hline
\end{tabular}

${ }^{\text {a } T h e ~ v a r i a b l e ~ g e n d e r ~ h a s ~ t w o ~ l e v e l s ~ w i t h ~ f e m a l e s ~ t a k e n ~ a s ~ t h e ~ r e f e r e n c e ~ c a t e g o r y ; ~}{ }^{\text {b}}$ The variable thyroiditis has three levels with "No thyroiditis" taken as the reference category, with the other two being Hashimoto's and nonspecific lymphocytic thyroiditis

carcinoma compared with females when age and thyroiditis type were kept fixed.

With increasing age, the proportion with papillary carcinoma significantly $(\mathrm{p}<0.001)$ decreased. The odds ratio was 0.957 (95\% CI $=0.934-0.981)$, which means with each year of increase in age, the odds of developing papillary carcinoma decreases by $4.3 \%$, for a given gender and thyroiditis type.

Those with nonspecific lymphocytic thyroiditis were more likely to have papillary carcinoma of the thyroid $(\mathrm{p}=0.002)$ than those without thyroiditis. Odds ratio for this was 2.557 (95\% CI = 1.397-4.680). Those with nonspecific lymphocytic thyroiditis are therefore 2.5 times more likely to have papillary carcinoma than those without thyroiditis, at a given age and gender.

Having Hashimoto's thyroiditis was not found to be associated with papillary carcinoma in this series (compared with not having thyroiditis or having nonspecific lymphocytic thyroiditis).
Only age was found to be a significant predictor for lymphovascular invasion in papillary carcinoma of the thyroid (Table 3). With increasing age, the proportion of those with lymphovascular invasion in those with papillary carcinoma significantly decreased $(p=0.010)$. The odds ratio was $0.913(95 \% \mathrm{CI}=0.852-0.979)$, meaning with each year of increase in age, the odds of developing papillary carcinoma decreases by $8.7 \%$.

None of the factors were significant predictors of capsular invasion in papillary carcinoma of thyroid according to the logistic regression analysis performed (Table 4).

Focality in papillary carcinoma of thyroid was also not predicted by any of the factors considered (Table 5).

When analyzing the relationship of tumor size with gender, age, and thyroiditis, multiple linear regression was used. According to the results, age was the only variable out of the three that became significant (Table 6). Therefore, the presence (or absence) of Hashimoto's thyroiditis and nonspecific lymphocytic thyroiditis was not 
Table 6: Multiple linear regression analysis output for tumor size in papillary carcinoma of thyroid

\begin{tabular}{llll}
\hline Model terms & $\begin{array}{l}\text { Estimate } \\
\text { (beta) }\end{array}$ & $\begin{array}{l}\text { Standard } \\
\text { error }\end{array}$ & $\begin{array}{l}\text { Significance } \\
(p)\end{array}$ \\
\hline Gender $^{\mathrm{a}}$ & -11.062 & 7.234 & 0.133 \\
Age & 0.653 & 0.256 & 0.014 \\
Hashimoto $^{\mathrm{b}}$ & 21.477 & 12.921 & 0.103 \\
Nonspecific $^{\mathrm{b}}$ & 3.193 & 5.977 & 0.596 \\
Constant (intercept) & 10.968 & 15.438 & 0.481 \\
\hline
\end{tabular}

${ }^{a}$ The variable gender was taken as a dummy variable with males coded 1 and females coded 0 ; ${ }^{\text {b}}$ The variables Hashimoto and nonspecific lymphocytic thyroiditis were taken as dummy variables with presence coded 1 and absence coded 0

found to be significant factors in predicting the size of thyroid tumors. Tumor size was shown to increase with advancing age.

When the 26 cases of follicular carcinoma were considered for logistic regression analysis, none of the factors were significant predictors of presence or absence of follicular thyroid carcinoma (Table 7).

Further analysis using logistic regression and multiple linear regression revealed that none of the factors were significant predictors of lymphovascular invasion, capsular invasion, focality, or tumor size in follicular carcinoma of thyroid according.

\section{DISCUSSION}

Papillary thyroid carcinoma is the commonest malignancy in the thyroid gland. Many factors had been studied to find out the causal relationship or as predictors of papillary thyroid carcinoma. In this study sample, presence of nonspecific lymphocytic thyroiditis, age, and gender were significant predictors of presence or absence of papillary thyroid carcinoma.

\section{Nonspecific Chronic Lymphocytic Thyroiditis associated with Increased Incidence of Papillary Thyroid Carcinoma}

The association between thyroid lymphoma and papillary thyroid carcinoma with chronic lymphocytic thyroiditis is well established in some parts of the world. But the influence of chronic lymphocytic thyroiditis on thyroid malignancy in our country is needed to be studied. Although they represent a spectrum of manifestations of chronic lymphocytic thyroiditis, various subtypes of thyroid lymphocytic infiltrate exist. The exact correlation and prognostic influences of these subtypes on differentiated thyroid carcinoma need to be assessed separately.

Lymphocytic thyroiditis is believed to be a disease with a range of histological features. One end of the spectrum represents Hashimoto's thyroiditis in which the thyroid tissue is affected secondary to immunemediated insult, showing destruction and replacement of thyroid tissue by an infiltrate of reactive lymphocytes forming lymphoid follicles with active germinal centers and follicular epithelium of remaining follicles showing diffuse oxyphilia.

The World Health Organization (WHO) in 1993 recommended iodization of the edible salt to prevent iodine deficiency. After the introduction of iodization program, the number of thyroiditis patients recorded in the countries who used iodide salt appeared to increase. In Australia, there was 50\% increase in thyroiditis. The animal studies reviewed that iodine in excess can destroy thyroid tissue, leading to different form of thyroiditis. ${ }^{23}$ The same WHO program was implemented in 1993 in Sri Lanka just after the WHO recommendations. Many studies done in Sri Lanka after initiation of the iodization program highlighted the use of unacceptable amount of iodine in different salt preparations. ${ }^{17}$ It was observed that most of these patients had higher prevalence of antithyroid peroxidase antibodies in contrast to the prevalence of antithyroglobulin antibodies. However, this study is still in the preliminary stages. ${ }^{24}$

After the year 2000, Sri Lankan pathologists throughout the country had noticed increased numbers of patients with thyroiditis who presented with diffuse enlargement of thyroid gland with nonspecific chronic inflammation of the thyroid, leading to chronic lymphocytic thyroiditis. Characteristically, these thyroids did not show Hurthloid changes seen in Hashimoto's thyroiditis, and the lymphoid cell infiltrate was not as destructive as

Table 7: Logistic regression analysis output for the presence of follicular carcinoma of thyroid

\begin{tabular}{|c|c|c|c|c|c|}
\hline \multirow[b]{2}{*}{ Model terms } & \multirow[b]{2}{*}{ Estimate (beta) } & \multirow[b]{2}{*}{ Significance $(p)$} & \multirow[b]{2}{*}{ Odds ratio } & \multicolumn{2}{|c|}{$95 \% \mathrm{Cl}$ for odds ratio } \\
\hline & & & & Lower & Upper \\
\hline Gender (male) ${ }^{a}$ & 0.601 & 0.289 & 1.824 & 0.601 & 5.534 \\
\hline Age & -0.007 & 0.676 & 0.993 & 0.961 & 1.026 \\
\hline Thyroiditis $^{\mathrm{b}}$ & & 0.726 & & & \\
\hline Thyroiditis (Hashimoto) & 0.024 & 0.975 & 1.024 & 0.229 & 4.583 \\
\hline Thyroiditis (nonspecific) & 0.366 & 0.428 & 1.442 & 0.583 & 3.566 \\
\hline Constant (intercept) & -2.960 & $<0.001$ & & & \\
\hline
\end{tabular}

aThe variable gender has two levels with females taken as the reference category; ${ }^{\text {b}}$ The variable thyroiditis has three levels with "No thyroiditis" taken as the reference category, with the other two being Hashimoto's and nonspecific lymphocytic thyroiditis. 
in Hashimoto's thyroiditis. Some of these patients with nonspecific chronic lymphocytic thyroiditis presented with well-differentiated thyroid malignancies. Some patients had two types of well-differentiated thyroid carcinomas (papillary and follicular) in the same thyroid. ${ }^{25}$ However, it is needed to study this entity of thyroiditis in greater detail with clinicopathological and serological correlation.

Most studies have used Hashimoto's thyroiditis and nonspecific chronic lymphocytic thyroiditis interchangeably in order to assess association of thyroiditis with thyroid malignancy. In different studies, the incidence of thyroid cancer developing against the background of chronic lymphocytic thyroiditis has been reported to be between 0.5 and $23 \% .^{4-6,26-29}$ Certain authors believe that there is a positive correlation between Hashimoto's thyroiditis (a subtype of chronic lymphocytic thyroiditis) and papillary thyroid carcinoma. ${ }^{3-9}$ Singh et $\mathrm{al}^{5}$ and Repplinger et $\mathrm{al}^{8}$ reported that the prevalence of thyroid cancer was significantly higher in patients with Hashimoto's thyroiditis compared with those without thyroiditis. In the present study, nonspecific chronic lymphocytic thyroiditis, a subtype of lymphocytic thyroiditis with similar histopathological features, was compared with the existence and influence on differentiated thyroid carcinoma, and the results revealed that nonspecific chronic lymphocytic thyroiditis were significant predictors of presence of papillary thyroid carcinoma, but not follicular thyroid carcinoma. Those with nonspecific chronic lymphocytic thyroiditis were 2.5 times more likely to have papillary thyroid carcinoma than those without thyroiditis, at a given age and gender.

Prognosis of thyroid cancers is affected by multiple clinicopathological factors, such as gender, age, tumor size, multifocality, capsular invasion, lymphovascular invasion, lymph node metastasis, and distant metastasis. ${ }^{30-32}$ However, the influence of coexisting nonspecific chronic lymphocytic thyroiditis on the behavior of thyroid carcinoma is still debatable. Although majority of studies showed a protective effect of associated chronic lymphocytic thyroiditis, some studies reported a worse prognosis while others pointed out that it does not affect its prognosis. ${ }^{18,19,33-38}$ Kashima et $\mathrm{al}^{18}$ reported a mortality and disease-free interval of 5 and $85 \%$ after 10 years among the patients without associated thyroiditis, compared with 0.7 and 95\% among cases with associated thyroiditis respectively. While lymphocytic infiltration is considered as an aggressive feature in breast and renal cell neoplasms, it is considered as a favorable prognostic indicator in hepatocellular carcinoma, melanoma, and transitional tumors of the bladder. But the association of lymphocytic infiltration in different patterns with thyroid malignancy, especially with differentiated thyroid carcinoma, is yet to be evaluated. Although immune cell infiltration among some malignant tumors has prognostic benefit, the presence of nonspecific chronic lymphocytic thyroiditis was not a significant predictor of focality, lymphovascular and capsular invasion in both papillary thyroid carcinoma and follicular thyroid carcinoma, indicating that the presence of nonspecific chronic lymphocytic thyroiditis does not change the morbidity in patients with thyroid malignancy in this sample. Malignancies in patients with chronic lymphocytic thyroiditis were not always multifocal even though thyroiditis diffusely affects the gland.

\section{With Increasing Age, the Proportion with Papillary Thyroid Carcinoma Significantly Decreases}

Although papillary thyroid carcinoma is common in middle age, some studies reported that with time, age distribution had changed in patients with papillary thyroid carcinoma. When the number of new papillary thyroid carcinoma cases were compared over the last 20 years, the age group with the most new cases shifted from patients aged 25 to 34 years to patients aged 45 to 54 years. Although all age groups had an increase in new papillary thyroid carcinoma cases, the largest increase occurred in patients aged 45 to 54 years with a10-fold increase over the past 20 years. ${ }^{39}$ But in our sample, the proportion of papillary thyroid carcinoma significantly decreased with increasing age.

\section{With Increasing Age, the Proportion of Lymphovascular Invasion in Patients with Papillary Carcinoma Significantly Decreases}

Thyroid cancer is unique among malignancies because age is an important prognostic indicator in the majority of staging systems. Multiple population-based studies, including the National Cancer Data Base report on 53,856 cases of thyroid cancer over a 10-year period and the Surveillance, Epidemiology, and End Results study on 15,698 thyroid cancer cases over an 18-year period, have found that age is an important independent prognostic indicator for well-differentiated thyroid cancer. ${ }^{40,41}$ Increase of mortality rate starts from 40 to 45 years. ${ }^{42}$ With the same degree of cancer involvement, patients aged $<45$ years have a distinctly different prognosis than those aged $>45$ years. Using the tumor-node-metastasis staging system for well-differentiated thyroid carcinoma, patients aged $<45$ years can have extensive distant metastases and, at maximum, have stage II disease, whereas if aged $>45$ years, tumor size, extrathyroidal extension, 
lymph node involvement, and distant metastases contribute to the classification of stage I to stage IV disease. ${ }^{43}$ But age was not a significant predictor of focality or capsular invasion in papillary thyroid carcinoma according to the logistic regression analysis of these data. With increasing age, the proportion of lymphovascular invasion in patients with papillary thyroid carcinoma significantly decreases. But age was not a significant predictor of presence of follicular carcinoma or lymphovascular or capsular invasion or focality in follicular carcinoma.

\section{Out of All Patients Who Underwent Thyroidectomy, Males were more Likely to have Papillary Thyroid Carcinoma Compared with Females}

Papillary thyroid carcinoma mainly affects women, with a female-to-male ratio of 5:1 in Korea compared with 2.5:1 in the UK. But in this sample of patients with goiters who underwent thyroidectomy, male patients carried a high risk of it to be malignant than the females with similar conditions.

\section{CONCLUSION}

There is a significant association between nonspecific chronic lymphocytic thyroiditis and papillary thyroid carcinoma. Incidence of nonspecific chronic lymphocytic thyroiditis was significant and may contribute to the increased incidence of papillary thyroid carcinoma. Patients with chronic lymphocytic thyroiditis, especially nonspecific chronic lymphocytic thyroiditis, should be appraised more carefully to exclude any coexisting malignancy, especially in the presence of other risk factors, such as male gender and young patients. Causes for increased incidence of nonspecific chronic lymphocytic thyroiditis, papillary thyroid carcinoma, and the influences of nonspecific chronic lymphocytic thyroiditis on the prognosis of the thyroid carcinoma with 5-year survival still need to be investigated with a larger sample size.

\section{REFERENCES}

1. Caturegli P, De Remigis A, Chuang K, Dembele M, Iwama A, Iwama S. Hashimoto's thyroiditis: celebrating the centennial through the lens of the Johns Hopkins hospital surgical pathology records. Thyroid 2013 Feb;23(2):142-150.

2. Konturek A, BarczyNski M, Wierzchowski W, Stopa M, Nowak W. Coexistence of papillary thyroid cancer with Hashimoto thyroiditis. Langenbecks Arch Surg 2013 Mar; 398(3):389-394.

3. Dailey ME, Lindsay S, Skahen R. Relation of thyroid neoplasms to Hashimoto disease of the thyroid gland. AMA Arch Surg 1955 Feb;70(2):291-297.

4. Hirabayashi RN, Lindsay S. The relation of thyroid carcinoma and chronic thyroiditis. Surg Gynecol Obstet 1965 Aug;121:243-252.
5. Singh B, Shaha AR, Trivedi H, Carew JF, Poluri A, Shah JP. Coexistent Hashimoto's thyroiditis with papillary thyroid carcinoma: impact on presentation, management, and outcome. Surgery 1999 Dec;126(6):1070-1076.

6. Ott RA, McCall AR, McHenry C, Jarosz H, Armin A, Lawrence AM, Paloyan E. The incidence of thyroid carcinoma in Hashimoto's thyroiditis. Am Surg 1987 Aug;53(8):442-445.

7. Okayasu I, Fujiwara M, Hara Y, Tanaka Y, Rose NR. Association of chronic lymphocytic thyroiditis and thyroid papillary carcinoma. A study of surgical cases among Japanese, and white and African Americans. Cancer 1995 Dec;76(11): 2312-2318.

8. Repplinger D, Bargren A, Zhang YW, Adler JT, Haymart M, Chen $\mathrm{H}$. Is Hashimoto's thyroiditis a risk factor for papillary thyroid cancer? J Surg Res 2008 Nov;150(1):49-52.

9. Kim KW, Park YJ, Kim EH, Park SY, Park DJ, Ahn SH, Park do J, Jang HC, Cho BY. Elevated risk of papillary thyroid cancer in Korean patients with Hashimoto's thyroiditis. Head Neck 2011 May;33(5):691-695.

10. Haymart MR, Repplinger DJ, Leverson GE, Elson DF, Sippel RS, Jaume JC, Chen H. Higher serum thyroid stimulating hormone level in thyroid nodule patients is associated with greater risks of differentiated thyroid cancer and advanced tumour stage. J Clin Endocrinol Metab 2008 Mar;93(3):809-814.

11. Holm LE, Blomgren $H$, Lowhagen T. Cancer risks in patients with chronic lymphocytic thyroiditis. N Engl J Med 1985 Mar;312(10):601-604.

12. Rago T, Di Coscio G, Ugolini C, Scutari M, Basolo F, Latofa F, Romani R, Berti P, Grasso L, Braverman LE, et al. Clinical features of thyroid autoimmunity are associated with thyroiditis on histology and are not predictive of malignancy in 570 patients with indeterminate nodules oncytology who had a thyroidectomy. Clin Endocrinol (Oxf) 2007 Sep;67(3): 363-369.

13. Crile G Jr. Struma lymphomatosa and carcinoma of the thyroid. Surg Gynecol Obstet 1978 Sep;147(3):350-352.

14. Anil C, Goksel S, Gursoy A. Hashimoto's thyroiditis is not associated with increased risk of thyroid cancer in patients with thyroid nodules: a single-center prospective study. Thyroid 2010 Jun;20(6):601-606.

15. Gasbarri A, Sciacchitano S, Marasco A, Papotti M, Di Napoli A, Marzullo A, Yushkov P, Ruco L, Bartolazzi A. Detection and molecular characterization of thyroid cancer precursor lesions in a specific subset of Hashimoto's thyroiditis. Br J Cancer 2004 Sep;91(6):1096-1104.

16. Prasad ML, Huang Y, Pellegata NS, de la Chapelle A, Kloos RT. Hashimoto's thyroiditis with papillary thyroid carcinoma (papillary thyroid carcinoma)-like nuclear alterations express molecular markers of papillary thyroid carcinoma. Histopathology 2004 Jul;45(1):39-46.

17. Wijeyaratne $C N$, Jayasinghe $A$, de Silva DG, Parkes $A B$, Lazarus JH, Premawardhana LD. Iodine prophylaxis, goitre and thyroid autoimmunity in Sri Lanka. Ceylon Med J 2005 Mar;50(1):20-23.

18. KashimaK, YokoyamaS,NoguchiS,MurakamiN, YamashitaH, Watanabe S, Uchino S, Toda M, Sasaki A, Daa T, et al. Chronic thyroiditis as a favorable prognostic factor in papillary thyroid carcinoma. Thyroid 1998 Mar;8(3):197-202.

19. Loh KC, Greenspan FS, Dong F, Miller TR, Yeo PP. Influence of lymphocytic thyroiditis on the prognostic outcome of patients with papillary thyroid carcinoma. J Clin Endocrinol Metab 1999 Feb;84(2):458-463. 
20. Schaffler A, Palitzsch KD, Seiffarth C, Höhne HM, Riedhammer FJ, Hofstädter F, Schölmerich J, Rüschoff J. Coexistent thyroiditis is associated with lower tumour stage in thyroid carcinoma. Eur J Clin Invest 1998 Oct;28(10):838-844.

21. Del Rio P, Cataldo S, Sommaruga L, Concione L, Arcuri MF, Sianesi $\mathrm{M}$. The association between papillary carcinoma and chronic lymphocytic thyroiditis: does it modify the prognosis of cancer. Minerva Endocrinol 2008 Mar;33(1):1-5.

22. Kebebew E, Treseler PA, Ituarte PH, Clark OH. Coexisting chronic lymphocytic thyroiditis and papillary thyroid cancer revisited. World J Surg 2001 May;25(5):632-637.

23. Kumarasinghe P. Morphologic assessment of thyroid disease by cytology and pattern of thyroid enlargement in Sri Lanka. J Ceylon Coll Physicians 1998;31(1-2):31-40.

24. Fernando RF, Chandrasinghe PC, Pathmeswaran AA. The prevalence of autoimmune thyroiditis after universal salt iodisation in Srilanka. Ceylon Med J 2012 Sep;57(3):116-119.

25. Ratnatunga PC, Amarasinghe SC, Ratnatunga NV. Changing patterns of thyroid cancer in Sri Lanka. Has the iodination program helped? Ceylon Med J 2003 Dec;48(4):125-128.

26. Matesa-Anić D, Matesa N, Dabelić N, Kusić Z. Coexistence of papillary carcinoma and Hashimoto's thyroiditis. Acta Clin Croat 2009 Mar;48(1):9-12.

27. Shih ML, Lee JA, Hsieh CB, Yu JC, Liu HD, Kebebew E, Clark OH, Duh QY. Thyroidectomy for Hashimoto's thyroiditis: complications and associated cancers. Thyroid 2008 Jul;18(7):729-734.

28. Diklić A, Zivaljević V, Paunović I, Kalezić N, Tatić S. Surgical procedures in patients with thyroid autoimmune disease. Srp Arh Celok Lek 2005 Oct;133(Suppl 1):77-83.

29. Strauss M, Laurian N, Antebi E. Coexistent carcinoma of the thyroid gland and Hashimoto's thyroiditis. Surg Gynecol Obstet 1983 Sep;157(3):228-232.

30. Koo BS, Yoon YH, Kim JM, Choi EC, Lim YC. Predictive factors of level IIb lymph node metastasis in patients with papillary thyroid carcinoma. Ann Surg Oncol 2009 May; 16(5):1344-1347.

31. Mercante G, Frasoldati A, Pedroni C, Formisano D, Renna L, Piana S, Gardini G, Valcavi R, Barbieri V. Prognostic factors affecting neck lymph node recurrence and distant metastasis in papillary microcarcinoma of the thyroid: results of a study in 445 patients. Thyroid 2009 Jul;19(7):707-716.

32. Sciuto R, Romano L, Rea S, Marandino F, Sperduti I, Maini CL. Natural history and clinical outcome of differentiated thyroid carcinoma: a retrospective analysis of 1503 patients treated at a single institution. Ann Oncol 2009 Oct;20(10):1728-1735.
33. Matsubayashi S, Kawai K, Matsumoto Y, Mukuta T, Morita T, Hirai K, Matsuzuka F, Kakudoh K, Kuma K, Tamai H. The correlation between papillary thyroid carcinoma and lymphocytic infiltration in the thyroid gland. J Clin Endocrinol Metab 1995 Dec;80(12):3419-3424.

34. Ozaki O, Ito K, Mimura T, Sugino K, Hosoda Y. Papillary carcinoma of the thyroid: tall-cell variant with extensive lymphocyte infiltration. Am J Surg Pathol 1996 Jun;20(6): 695-698.

35. Pellegriti G, Belfiore A, Giuffrida D, Lupo L, Vigneri R. Outcome of differentiated thyroid cancer in Graves' patients. J Clin Endocrinol Metab 1998 Aug;83(8):2805-2809.

36. Ozaki O, Ito K, Kobayashi K, Toshima K, Iwasaki H, Yashiro T. Thyroid carcinoma in Graves' disease. World J Surg 1990 May-Jun;14(3):437-440.

37. Muzza M, Degl'Innocenti D, Colombo C, Perrino M, Ravasi E, Rossi S, Cirello V, Beck-Peccoz P, Borrello MG, Fugazzola L. The tight relationship between papillary thyroid cancer, autoimmunity and inflammation: clinical and molecular studies. Clin Endocrinol (Oxf) 2010 May;72(5):702-708.

38. Huang BY, Hseuh C, Chao TC, Lin KJ, Lin JD. Well-differentiated thyroid carcinoma with concomitant Hashimoto's thyroiditis present with less aggressive clinical stage and low recurrence. Endocr Pathol 2011 Sep;22(3):144-149.

39. David T, Hughes, Megan R, Haymart, Barbra S, Miller, Paul G, et al. The most commonly occurring papillary thyroid cancer in the United States is now a microcarcinoma in a patient older than 45 years Thyroid 2011;21: 231-236.

40. Hundahl SA, Fleming ID, Fremgen AM, Menck HR. A National Cancer Data Base report on 53,856 cases of thyroid carcinoma treated in the U.S., 1985-1995. Cancer 1998 Dec;83(12):2638-2648.

41. Gilliland FD, Hunt WC, Morris DM, Key CR. Prognostic factors for thyroid carcinoma: a population-based study of 15,698 cases from the Surveillance, Epidemiology and End Results (SEER) program 1973-1991. Cancer 1997 Feb;79(3):564-573.

42. Mazzaferri EL, Kloos RT. Current approaches to primary therapy for papillary and follicular thyroid cancer. J Clin Endocrinol Metab 2001 Apr;86(4):1447-1463.

43. Dean DS, Hay ID. Prognostic indicators in differentiated thyroid carcinoma. Cancer Control 2000 May-Jun;7(3): 229-239.

44. Greene, FL.; Page, DL.; Fleming, ID.; FritzAG.; Balch, CM.; Haller, DG.; Morrow, M.; editors. Thyroid. In: American Joint Committee on Cancer: cancer staging manual. 6th ed. New York: Springer-Verlag; 2002. pp. 77-87. 